\title{
Formulation and Characterization of PAI-PTFE-cg Antifriction Coatings
}

\author{
Michaela Gedan-Smolka ${ }^{1,}$ a $^{*}$, Anne Marschner ${ }^{1}$, Dieter Lehmann ${ }^{1}$, \\ Rainer Franke ${ }^{2, b}$, Marco Klemm², Erhard Leidich ${ }^{3, c}$ and Björn Prase ${ }^{3}$ \\ ${ }^{1}$ Leibniz-Institut für Polymerforschung Dresden, Hohe Str. 6, 01069 Dresden, Germany \\ ${ }^{2}$ Struktur- und Werkstoffmechanikforschung (SWM) at Technical University Dresden, Wilhelmine- \\ Reichard-Ring 4, 01109 Dresden, Germany \\ ${ }^{3}$ Institut für Konstruktions- und Antriebstechnik (IKAT) at Technical University Chemnitz, 09111 \\ Chemnitz, Germany \\ a mgedan@ipfdd.de, ${ }^{\mathrm{b}}$ rainer.franke@swm-dresden.de, ${ }^{\mathrm{c}}$ erhard.leidich@mb.tu-chemnitz.de
}

Keywords: PAI, PTFE, PAI-PTFE-cg dispersion, solid lubricant

\begin{abstract}
Polytetrafluoroethylene (PTFE) powder is used as a solid lubricant in commercial antifriction coatings. However, most of the matrix polymers are usually not compatible with virgin PTFE resulting in low dispersion and mechanical film stability and adhesion. In our research PTFE TF 2025 was irradiated by $\gamma$-beam generating PTFE micropowder with persistant radicals and functional groups. These functional groups are able to perform a chemical grafting (cg) of polyamideimide (PAI) and modified PTFE-micropowder by reactive extrusion in melt. Based on grinded extrudates PAI-PTFE-cg dispersions were formulated followed by characterizing dispersion as well as film properties. It was found, that PAI-PTFE-cg dispersion comprises very small PTFEparticles at higher $\gamma$-irradiation doses in homogeneous dispersions. In addition, all samples showed outstanding film flexibility. Basic tribological properties under mixed lubrication were studied by using a ring-on-disk tribometer. Finally, diluted dispersions were applied to a multi-surface sliding bearing (four segments) for testing in a hydrodynamic plain test bench.
\end{abstract}

\section{Introduction}

It is well known that polytetrafluoroethylene (PTFE) and polyamideimide (PAI) exhibit outstanding properties. Especially the high temperature stability of both polymers makes them interesting for high performance applications in several areas. In the field of antifriction coatings a combination of both virgin polymers has been industrially available for quite some time. Because of its very low coefficient of friction PTFE, depending on the used amounts, acts as a solid lubricant and is able to enhance the antifriction properties of the PAI film on top of a substrate. However, the very low surface energy of PTFE usually prevents a reliable and stable homogenization of both materials in the dispersion as well as in the final film. Without adding any dispersion stabilizer the PTFE particles tend to agglomerate during the storage of the dispersion or during the curing procedure very fast. Furthermore, the incompatibility of PTFE and PAI leads to the formation of voids. Especially bigger PTFE-particles or agglomerates so can result in "breaking points" under mechanical load reducing the total film flexibility and wear resistivity at the end. As already described, in order to get a better compatibilization between PTFE and other matrix polymers PTFE fine powder can be radiation modified by $\beta$ - or $\gamma$-beam generating persistant radicals and functional groups $(\mathrm{COF}, \mathrm{COOH})[1,2]$. Hence, the so treated powders can even be linked covalently with high performance plastics, e.g. PEEK, as reported in the past $[3,4]$. A chemical grafting of PAI is successful by reactive extrusion in melt [5]. Subject of the paper is the use of chemically grafted (cg) PAI-PTFE for the formulation of sliding lacquer dispersions, their application to steel blanks followed by a characterization of coating properties and their tribological behavior. 


\section{Materials}

PAI Torlon 4000 T (Solvay), PTFE TF 2025 (Dyneon/3M), NMP EMPLURA ${ }^{\circledR}$ (Merck), Aerosil ${ }^{\circledR}$ R 972 (Evonik), Xylane ${ }^{\circledR} 1070$ (Whitford)

\section{Methods}

Transmission light microscopy. Dispersion properties were characterized by using an Olympus BX 51 with camera Olympus UC 30.

Rheological measurements. These measurements were done by an Anton Paar MCR 301, with plate-plate PP 50 at $24^{\circ} \mathrm{C}$. Rotational measurements have been carried out with the following steps: 1. Stepwise increase of shear rate in the frequency range $0.01-10001 / \mathrm{s}$ within $90 \mathrm{~s}, 2$. Maintain at $10001 / \mathrm{s}$ for $90 \mathrm{~s}, 3$. Sweep back to $0.011 / \mathrm{s}$ within $90 \mathrm{~s}$.

Dispersion application. The dispersions were applied to either steel gradient oven sheets (Steel ST $37-2,1 \mathrm{~mm}$ thickness, pretreated) by doctor blade or steel testing species (Steel C 10; $40 \mathrm{~mm} \times 40$ $\mathrm{mm}, 10 \mathrm{~mm}$ thickness) by spraying for tribological testing. The substrate surfaces for the last were pretreated by an industrial pretreatment procedure (corundum blasted and iron phosphated). For the evaluation of film properties the lacquers were applied to corundum blasted and zinc phosphated steel gradient oven sheets.

The curing of the sheets proceeded in an oven by using various curing procedures:

I $80{ }^{\circ} \mathrm{C} / 45 \mathrm{~min} \rightarrow 120^{\circ} \mathrm{C} / 60 \mathrm{~min} \rightarrow 170^{\circ} \mathrm{C} / 60 \mathrm{~min} \rightarrow 225^{\circ} \mathrm{C} / 3 \mathrm{~h}$

II $80{ }^{\circ} \mathrm{C} / 45 \mathrm{~min} \rightarrow 120^{\circ} \mathrm{C} / 60 \mathrm{~min} \rightarrow 160^{\circ} \mathrm{C} / 60 \mathrm{~min} \rightarrow 200^{\circ} \mathrm{C} / 1 \mathrm{~h}$

The film thickness for the gradient oven sheets was in the range between $\sim 10$ and $\sim 30 \mu \mathrm{m}$ and for the four-shaft sliding bearing $26.5 \pm 2.6 \mu \mathrm{m}$.

Mechanical film properties. The static film flexibility was tested using an Erichsen Cupping tester (Erichsen) according to DIN EN ISO 1520 standard. Impact and reverse impact tests were carried out by an Impact tester (Byk Gardner) according to ASTM 2794.

Tribological properties. Since the investigations were to provide a comparison of load parameters to earlier works on thermoplastic and thermosetting compounds, a simple model test machine according DIN ISO 7148-1 was used. The friction of a ring against a plate is simulated with a tribometer according to SIEBEL/KEHL [6] for the load conditions given in Table 1.

Table 1. Load conditions for friction measurements according to SIEBEL/KEHL

\section{Condition}

\section{Parameter}

$\begin{array}{ll}\text { Counterpart } & \text { Carbon steel C45 }\left(\varnothing_{\text {out }}=28 \mathrm{~mm},\left(\varnothing_{\text {in }}=26 \mathrm{~mm}\right), 33 \pm 2 \mathrm{HRC}, \mathrm{Ra}=0.2 \mu \mathrm{m}\right. \\ \text { Ground part } & \text { PAI-PTFE-cg coated carbon steel C10 plates } \\ \text { Lubricant } & \text { Turbine oil Renolin Eterna 32 } \\ \text { Sliding speed } & \mathrm{v}=0.9 \mathrm{~m} / \mathrm{s} \\ \text { Initial pressure } & \mathrm{p}_{0}=5 \mathrm{MPa} \\ \text { Oil temperature } & \mathrm{T}_{\mathrm{P}}=50^{\circ} \mathrm{C} \\ \text { Testing time } & \mathrm{t}_{\mathrm{B}}=22 \mathrm{~h} \text { with measure intervals at } \mathrm{t}_{\mathrm{B}}=0.08 / 0.17 / 0.33 / 0.5 / 1 / 2 / 4 \text { and } 6 \mathrm{~h}\end{array}$

Application oriented tribological testing. Therefore, the favored lacquer formulation was applied to a multi-surface (four segments) sliding bearing by spraying. All practical tests were performed on a hydrodynamic plain test bench GL 110 (Fig. 1) [7]. Based on the basic properties for mixed lubrication, the assessment of damage tolerance was evaluated. The mean pressure for the emergency tests was 2 respectively $4 \mathrm{MPa}$ and the maximum sliding speed $3600 \mathrm{RPM}$. The focus was on abrasive wear (localized melting) and on the temperature development respectively power loss. Emergency testing, which represents the most extreme application conditions, was carried out in three different variations (Fig. 2). 


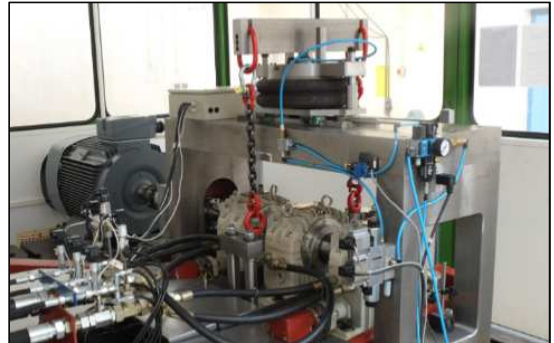

a)

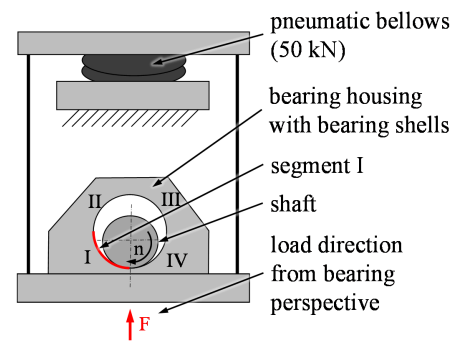

b)

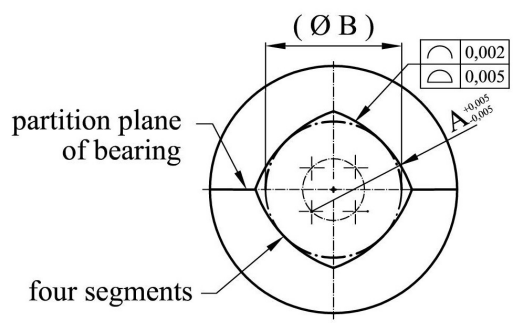

c)

Fig. 1. a) Overview; b) Schematic structure of the loading device with segmentation c) bearing profile: B/ 0.74 , Sliding surfaces eccentricity 0.5 , bearing clearance $2 \%$; coating thickness:

Bearing alloy $\mathrm{SnSb8Cu} 4=5 \mathrm{~mm}, \mathrm{PAI}-\mathrm{PTFE}-\mathrm{cg}$ coating $=25 \mu \mathrm{m}$

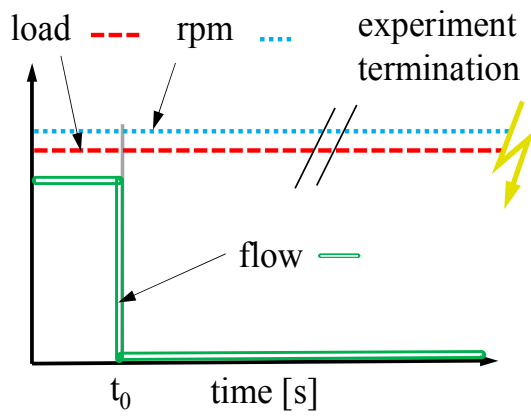

a) Complete interruption

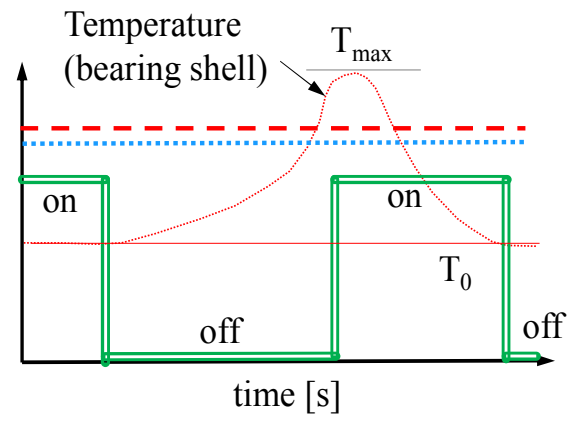

b) Cyclical interruption

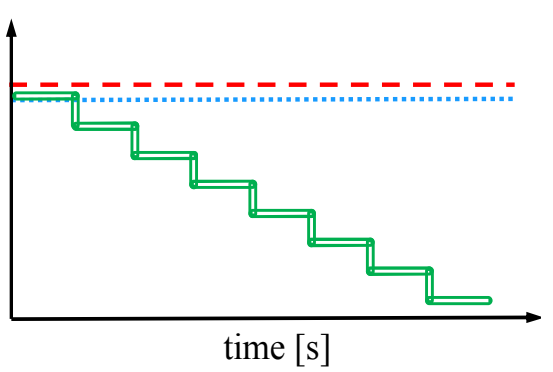

c) Stepwise reduction

Fig. 2. Schematic representation of the kinds of emergency test with different oil supply

\section{Results and Discussion}

Initially the virgin PTFE-powder was modified by $\gamma$-irradiation with a dose of 200/500/700 kGy in the same manner as it has been already described for the recycling of sintered PTFE waste earlier [8]. In the next step the origin PAI was chemically grafted with $20 \% \mathrm{w} / \mathrm{w} \gamma$-modified TF2025 by reactive extrusion in a Haake Rheocord PolyLab 300 p. Afterwards, the extrudate was grinded followed by a dispersion of the powder in NMP ( $50 \mathrm{~g}$ powder $/ 150 \mathrm{ml}$ NMP) by using a Dispermat ${ }^{\circledR}$ LC30 $\left(80^{\circ} \mathrm{C}, 10.000 \mathrm{U} / \mathrm{min}, 4 \mathrm{~h}\right)$. These concentrations were only used for doctor blade application (GL67).

Dispersion and film properties. Transmission light micrographs showed very fine and almost globular particles for sliding lacquers by using PTFE which was irradiated at 500 (GL99 is identical to GL94) or $700 \mathrm{kGy}$ (GL92). In contrast, the TF 2025 particles in GL93, which were treated with a $200 \mathrm{kGy}$ dose, are larger and exhibit a more fibrous structure because of the lower degradation of PTFE chains (Fig.3).

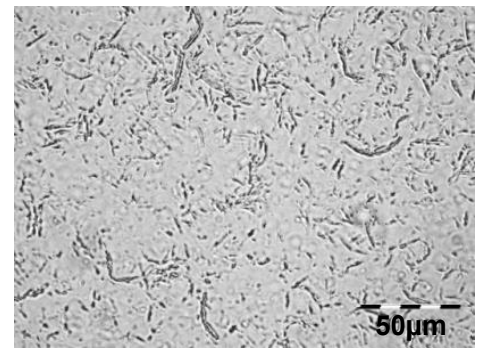

a)

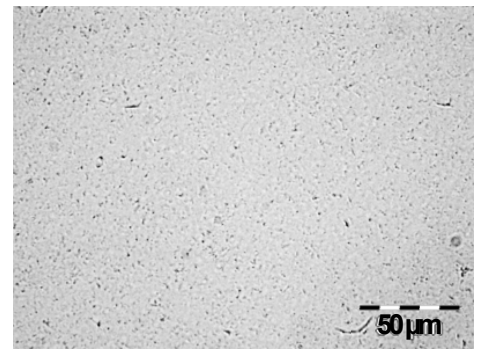

b)

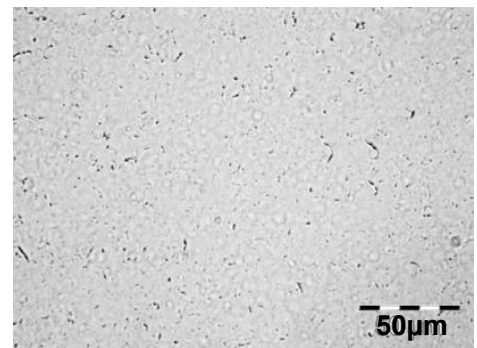

c)

Fig. 3. Transmission light microscopy of the sliding lacquer dispersion a) GL93 (200 kGy)

b) GL94/99 (500 kGy) c) GL 92 (700 kGy) 
Rheological measurements of the basic lacquer dispersion GL67 proved a shear thinning behavior within a shear rate up to 1000 1/s. The cured films (thickness of dry film between 10 and $25 \mu \mathrm{m}$ ) on zinc phosphatized steel sheet substrates are highly flexible against quasi static load and impact stress almost independent of the PTFE-irradiation dose and curing procedure (Table 2).

Table 2. Mechanical properties of antifriction coatings on zinc phosphatized steel sheets

\begin{tabular}{lcccccc} 
Sliding lacquer & $\begin{array}{c}\text { Curing } \\
\text { condition }\end{array}$ & $\begin{array}{c}\mathbf{d}_{(\text {wet) }} \\
{[\boldsymbol{\mu m}]}\end{array}$ & $\begin{array}{c}\mathbf{d}_{(\mathbf{d r y})} \\
{[\boldsymbol{\mu m}]}\end{array}$ & $\begin{array}{c}\text { Erichsen- } \\
\text { cupping } \\
{[\mathbf{m m}]}\end{array}$ & $\begin{array}{c}\text { Impact [160 inch*Ib] } \\
\text { dir }\end{array}$ & rev \\
\hline GL67/700 kGy & I & 200 & 24.3 & 6.6 & + & + \\
GL92/700 kGy & II & 100 & 19.2 & 8.0 & + & + \\
GL99/500 kGy & II & 100 & 22.5 & 7.2 & + & + \\
GL93/200 kGy & II & 100 & 11.6 & 7.4 & + & + \\
\hline
\end{tabular}

For the spray application to the tribological test specimens the lacquer dispersion has to be diluted with NMP. This approach resulted in a Newton's behavior of the dispersion above adding of approximately $15 \%$ additional solvent. For that reason the lacquer was modified by adding an sufficient amount of Aerosil to recover the shear thinning behavior and to reach similar rheological properties as found in the industrial available lacquer Xylan ${ }^{\odot} 1070$ (Fig. 4). However, it has to be taken into account that for future industrial spray application a further optimisation of the resulting basic lacquer formulation is a mandatory requirement.

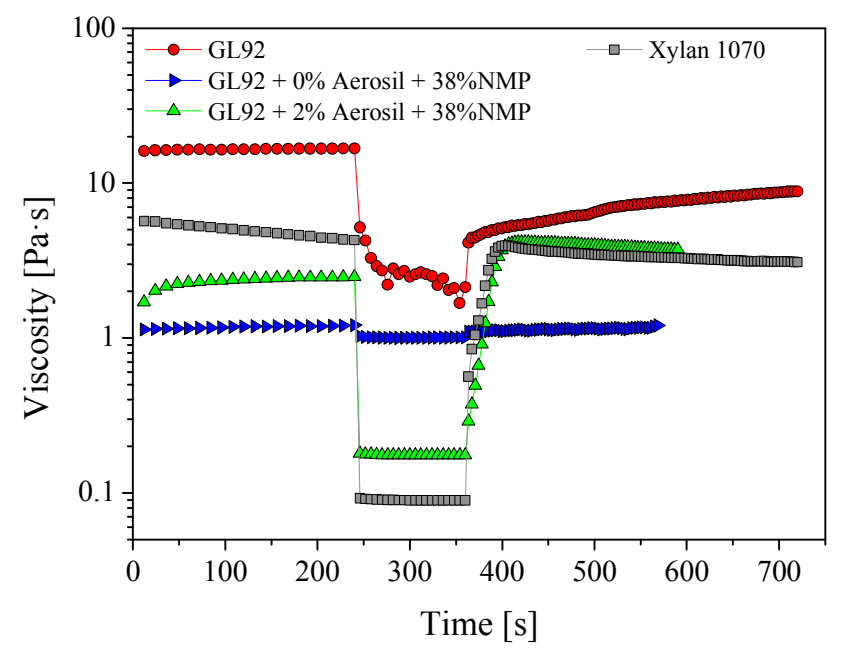

Fig.4. Changes in rheological behavior during dispersion optimization for spray application

Basic tribological testing. Under mixed lubrication conditions the sliding lacquers with a coating thickness lower than $20 \mu \mathrm{m}$ show after a testing time of about 0.5 hours a failure due the low bonding strength. For all thicker coatings of the sliding lacquer variants with different thinning states and curing procedures the specific wear rate lies in a range between $1.52 \cdot 10^{-8}$ and $4.55 \cdot 10^{-8}$ $\mathrm{mm}^{3} / \mathrm{Nm}$ with a small scatter (Fig. 5). The friction coefficient shows characteristic values for the load conditions. 

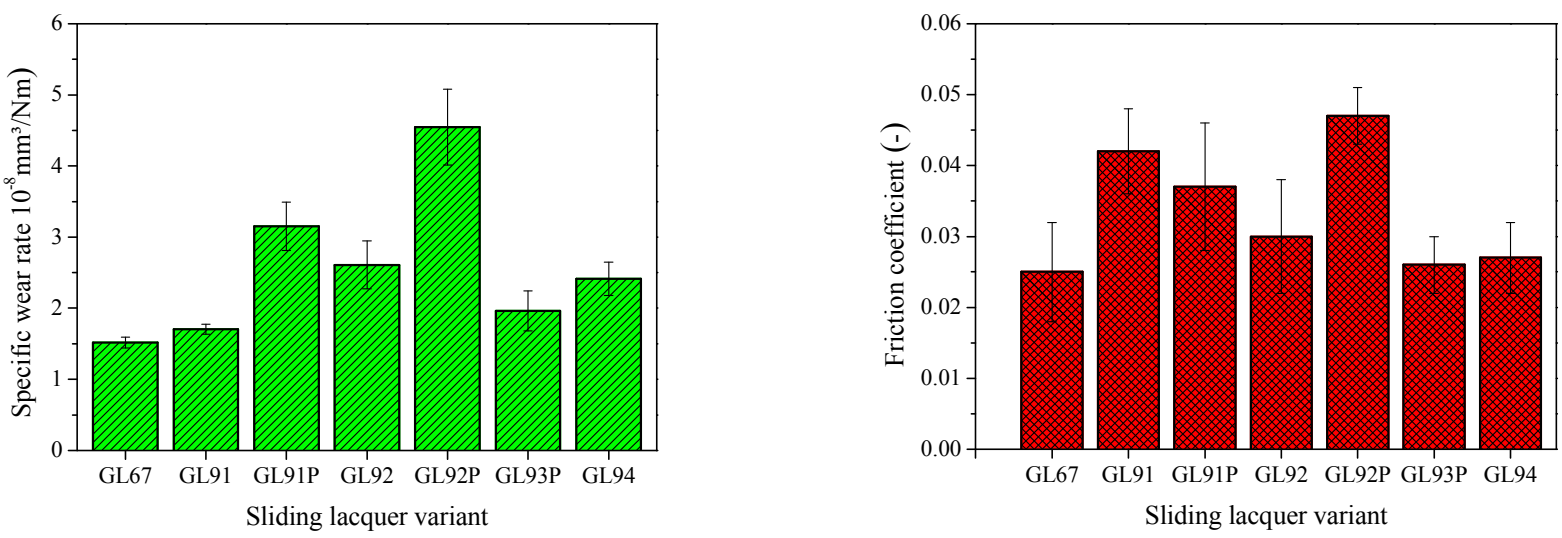

Fig.5. Specific wear rate and friction coefficient at testing time $t_{B}=22$ hours for different sliding lacquer variants without and with iron phosphate as interlayer $(\mathrm{P})$

Four-shaft sliding bearing. The emergency tests without oil of the sliding lacquer GL92 in comparison with conventional bearing alloy $\mathrm{SnSb8Cu} 4$ show full melting of the bearing alloy in the lower bearing shell. The bearing and the shaft are fully destroyed. In contrast, the bearing system with alternative sliding lacquer (GL92) local failed as a result of the seizing of the rotor due increasing of the bearing temperature. The shaft was undamaged. This is caused by a thin transfer film of the shaft surface. For the evaluation of the occurrence of damage, the emergency testing with cyclical interruption of the oil supply experiments were interrupted after 1, 5, 10, 50, 100 and 500 load cycles. The bearing variant with sliding lacquer showed no significant damage after 500 load cycles. In contrast, the bearing alloy melts and the system was destroyed. It was found that failure of the bearing alloy had already occurred after the first load cycle, Fig. 6.

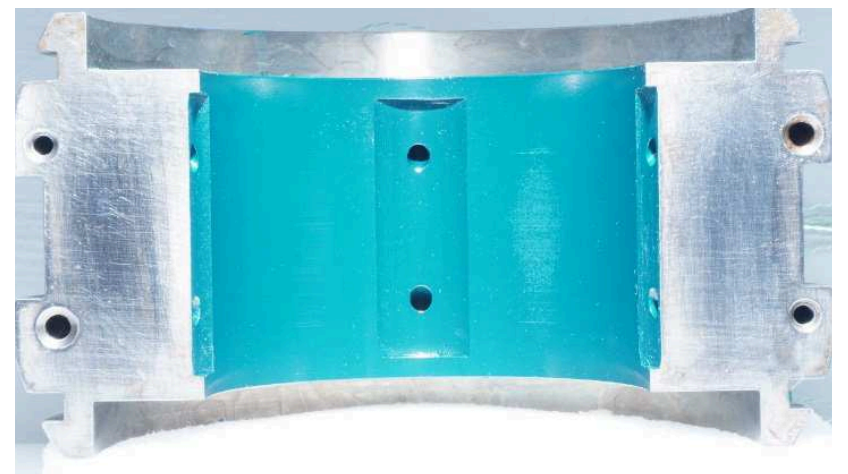

a) Sliding lacquer GL92, smooth running-in area visible on the lower shell

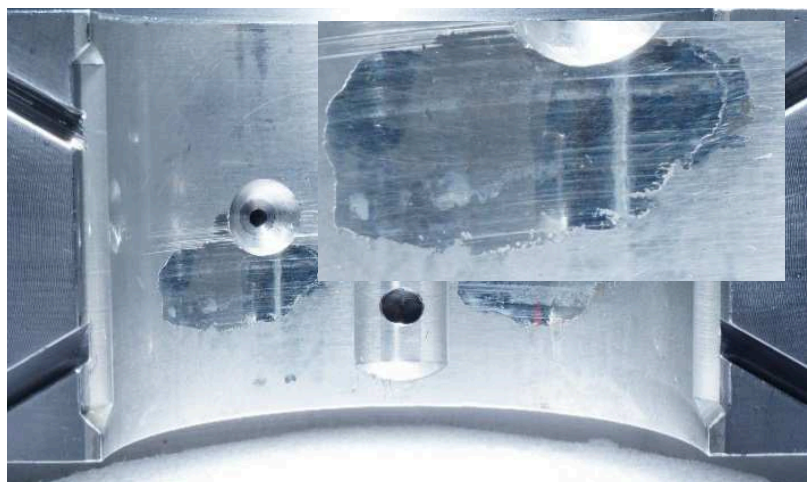

b) $\mathrm{SnSb8Cu} 4$, molten alloy of the lower bearing shell

Fig. 6. Failure patterns from emergency testing with cyclical interruption of the oil supply

Testing with a stepwise reduction of the oil supply was performed exclusively on the bearing with the sliding lacquer. Previous studies have shown that the bearings with bearing alloy $\mathrm{SnSb} 8 \mathrm{Cu} 4$ fail very fast. Furthermore, the tests have demonstrated that a reduction in the power loss of up to $75 \%$ is possible.

\section{Conclusions}

Within the property- and application-oriented development and optimization of friction coatings it was possible to produce different sliding lacquers on an industrial scale and to apply by conventional spray technology on substrates or bearing shells.

Tribological model experiments on the optimized sliding lacquers showed that a minimum layer thickness of 20 microns is required to achieve acceptable wear properties. The studies also revealed 
that pretreatment of substrates by Fe-phosphating may be advantageous. Furthermore, it has been determined that an optimal curing process is required for thin coatings in order to influence the layer-substrate bonding positively.

The investigation has proven that chemical grafted PAI-PTFE is a technically useful alternative to conventional wear layers $(\mathrm{SnSb8Cu} 4)$. In the functional evaluation of coated bearing shells turned out that all tested sliding lacquers have a very high wear resistance. Enforced emergency tests disclosed the enormous potential of sliding lacquers. After a short interruption of the oil supply for a period of three hours, no wear occurred (Bearing reference alloy $\rightarrow$ partial melting). Static and dynamic tests confirmed the expectations. Due to the extreme wear resistance of the sliding lacquers the oil flow for power loss reduction could be significantly reduced (reduction of power loss of up to $75 \%$ ) within the experiments.

\section{Acknowledgements}

The authors thank the BMWi and the AiF (grant IGF 17705 BR) for financial support.

\section{References}

[1] K. Lunkwitz, U. Lappan, U. Scheler, Modification of perfluorinated polymers by high-energy irradiation, Journal of Fluorine Chemistry 125 (2004) 863-873.

[2] T. Hoffmann, M. Heller, D. Jehnichen, T. Engelhardt, D. Lehmann, Influence of Absorbing Materials on the Funtionalization of Poly(tetrafluoroethylene) During $\gamma$-Irradiation, J. of Applied Polymer Science 130 (2013) 1787-1793.

[3] A. Taeger, T. Hoffmann, W. Butwilowski, M. Heller, T. Engelhardt and D. Lehmann, Evidence of chemical compatibilization reaction between poly(ether ether ketone) and irradiationmodified poly (tetrafluoroethylene), High Performance Polymers 26 (2014) 188-196.

[4] A. Frick, D. Sich, G. Heinrich, D. Lehmann, U. Gohs, C. Stern, Properties of Melt Processable PTFE/PEEK Blends: the Effect of Reactive Compatibilization Using Electron Beam Irradiated Melt Processable PTFE, J. Appl. Polym. Sci. 128 (2013) 1815-1827.

[5] M. Gedan-Smolka, D. Lehmann, A. Marschner, K. Kunze, R. Franke, I. Haase, Chemisch kompatibilisierte PAI-PTFE-cg-Gleitlacke, 52. Tribologie-Fachtagung Göttingen, Proceedings volume I (2011) No. 21, ISBN 978-3-00-035439-7.

[6] R. Franke, D. Lehmann \& K. Kunze, Tribological behaviour of new chemically bonded PTFE polyamide compounds. Wear, 262, 3-4 (2007) 242-252.

[7] E. Leidich, B. Prase, Characteristics of hydrodynamic plain bearings with bonded coating, The 17th Nordic Symposium on Tribology - NORDTRIB 2016, June 14-17, Aulanko, Hämeenlinna, Finland (2016) 219.

[8] T. Hoffmann, M. Heller, T. Engelhardt, A. Taeger, H. Marks, D. Lehmann, Strahlenchemisches Recycling von PTFE-Materialien, GAK: Gummi Fasern Kunststoffe 65 (2012) 784-789. 